\title{
The Sound of Freedom
}

\section{US Military Aircraft Noise in Okinawa, Japan}

RUPERT COX

Manchester U

"Our mission," said Major Hutcheson, public relations officer at Kadena, USAF base in Okinawa, Japan, "is to put planes in the air." It was a blunt, typically frank and well-rehearsed response to my inquiry which, like my visit to the base, was about the regulation of mechanical noise-specifically that generated by aircraft taking off and landing at the base-through working practices, environmental health criteria and testing and architectural regulations. The issue of aircraft noise at Kadena has been a widely reported and intensively researched source of public health concerns for the communities living outside the base, bringing Okinawan identity politics into collision with national strategic interests in Tokyo and Washington. The planes heard in the air over Kadena, like the helicopters above Futenma, the nearby US marine base whose stalled relocation caused the resignation of Japanese Prime Minister Hatoyama, operate from land still owned in significant proportions by locals living around their perimeters. The sonic activity of these bases is a direct legacy of the land's appropriation and military use by US troops after the 1945 Battle of Okinawa and the subsequent collusion of the Japanese government in enforcing the leasing agreements and annual host-nation support payments to cover infrastructure and operation. More broadly, the sonic traffic of aircraft from Kadena-the largest and most strategically important US airbase in East Asiaindexes US foreign policy in the region and the conflicts in Korea, Vietnam, the Gulf War, Iraq and Afghanistan that it supported.

\section{Politics of Frequency}

The sonic trajectories of these national histories emerge partially but powerfully from the acoustic survey measurements and medical questionnaires of Okinawans who live in their audible domains. They were subjects of an intensive epidemiological study of the effects of aircraft noise, conducted at the request of Okinawa's prefectural government in1993 and led by Kozo Hiramatsu (UK president, Japan Society for the Promotion of Science). The survey data showed the negative effects of aircraft noise in areas of everyday life (sleeping patterns, speech communication and TV viewing), general health (high blood pressure and psychosomatic neurosis), children's behavior (reduced immunity to colds, appetite and ability to make friends), infant birth weight (showing a significant increasing trend of the rate of low birth weight) and hearing loss. Although not specifically designed as such, the research process established close relationships with some residents, which for Hiramatsu revealed aspects of acoustic experiences that were not discernable in the statistical data. These had to do with the ways that the persistent, sudden occurrences of aircraft noise into the midst of everyday lives recalled traumatic wartime experiences and with how the reverberant affects of jet engines made the postwar changes in the topog- raphy of urban and natural features of the surrounding coastline discernable as a sense of place, something that could be elicited in conversation and listening together to recordings of these sounds, but not through acoustic measurements.

Our subsequent collaboration was built on the understanding of the possibilities of what Steven Feld has called for in a dialogic anthropology of sound and by sound recording and editing methodologies and led eventually to my visit to the base mentioned above, where aircraft sound is conceived and managed differ-

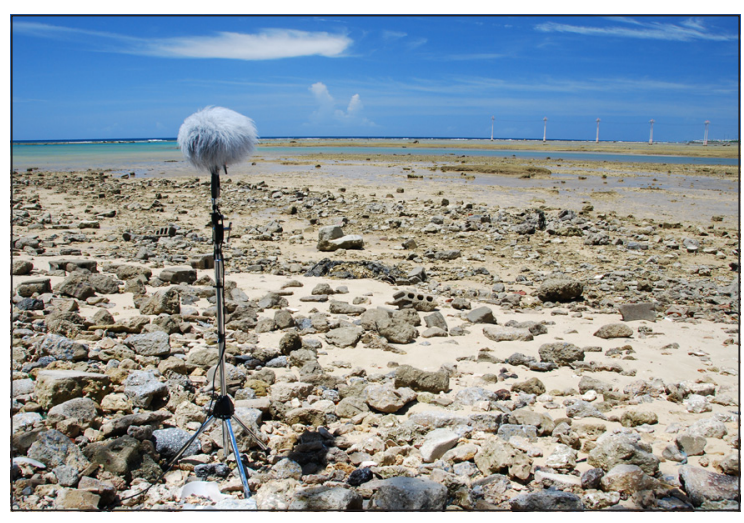

Sunabe Beach at end of Kadena runway. Photo courtesy Rupert Cox

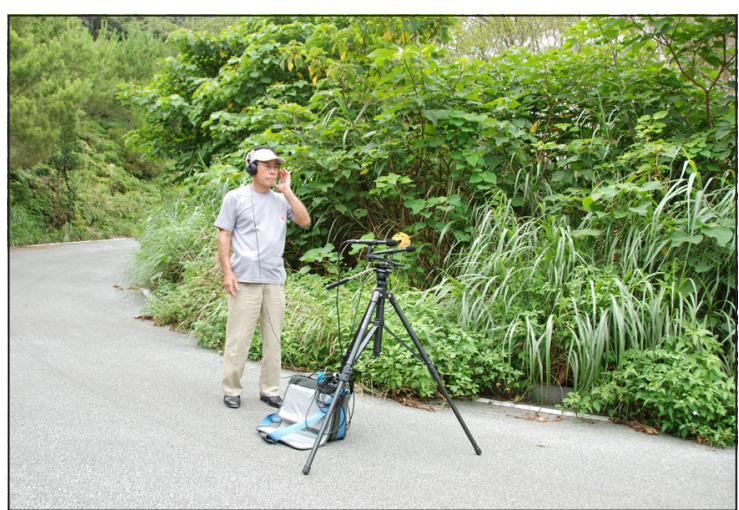

Yogi san listening to the Yanbaru forest and artillery fire of Marine Corps base Camp Hansen. Photo courtesy Rupert Cox

ently as part of a positive construction of on-base, military life. Such a methodology in this case involved critically questioning the processes of transduction and the psycho-acoustic models of hearing built into the design of the different sound-level monitoring devices deployed by the Japanese government on behalf of the US military and by protesting Okinawan community groups. These devices became a point of legal contest in their dispute over the ill effects of aircraft noise and revealed that the acoustic vibrations and sonic frequencies resonate with measurable effect but profoundly different significances for those living on either side of the base's boundary fence. They are an example of what Steve Goodman in his book Sonic Warfare (MIT Press, 2010) has called a "sensuous mathematics" of a "politics of frequency," and as such can be understood as cultural metaphors of US triumphalism and Okinawan resistance.

\section{Sound of Freedom}

For many former and serving members of the USAF and their supporters, the sound of overflying US Air Force jets, typically at low level and great speed, denotes a "sound of freedom." This is a concept deployed as a strategic show of force in conflict zones such as Afghanistan and Iraq, as well as being a title of choice for many air displays in the US. It is a progressive, modernist notion of aircraft noise with diverse roots in Italian futurism, in the critical writings on war and speed of Paul Virilio and in US popular culture where in an iconic film such as Top Gun, jet engine noise merges with music and character to drive a military narrative about American ascendancy.

The sound of freedom makes a sonic fetishism of the sleek lines of a fast-flying military jet, taking off from the flat, wide expanse of Kadena's runway into the Pacific sky. It contrasts dramatically with the forms of visuality that characterize Okinawan responses to the aura legacies of the postwar, such as the vibration induced, blurred shape of a B52 bomber taking off from Kadena in a famous image (1972) by the photographer Tomatsu Shomei and the coarse stone texture and expressive contours of the sanshin-an Okinawan stringed instrument-player, created by the war-artist Minoru Kinjo at the center of his sculptural relief that adjoins the entrance to the cave of Chibi-chiri-gama, site of one of the Battle of Okinawa's most infamous mass suicides. The blurred lines of these compositions reveals a dark impressionism and evokes a sensory register of remembering the postwar, which in the case of aircraft sound eludes the scientific certainties presented by the rational system of lines that constitute noise maps, just as they resist the sense and sensibilities of the sound of freedom

For those who live and work inside or outside the boundary fence of Kadena, hearing the sounds of overflying aircraft is never simply or directly about their volume and rate of recurrence for it is part of a synaesthetic memory of the senses, ontologically different from the digital memory of a sound level meter. Heard as a "sound of freedom," jet engine noise is a materialization of forms of relationality between bodies, spaces and machines. These are directed cohesively toward the achievement of strategic aims and may discursively reproduce the cultural intimacies of family and nation. Heard as an echo of lost family lands, of sites of forgotten atrocities, of the diminishing vitality of culturally valuable resources such as the lagoon (ino) at the end of Kadena's runway and as sudden and unexpected ruptures of domestic and working life, the relational forms of aircraft sound are disruptive and dispersive. These forms can potentially be made manifest through processes of sound recording and shared listening as our experience of collaborating with one former leader of the small district of Sunabe, located beside the ocean and Kadena's runway, bore out.

Yogi san has heard the sound of aircraft from his house close to Kadena's boundary fence for over 40 years, but the heightened performativity of listening together to recordings that we had made of jets taking

See Sound of Freedom on page 14 


\author{
Andalusi Music \\ continued from page 9
}

\section{Circulating Theory}

Thinking about music in terms of circulation might help elucidate what has been going on in a case such as the modern Algiers-Tlemcen tradition, but it is a two-way street. On the one hand, thinking about music in terms of circulation has made me think about the work that goes into delineating, maintaining and moving musical goods. On the other hand, it demands new ways of thinking about circulation. Music may be like Weiner's textiles, but there are also important differences. Its evanescence implies that in the absence of audio recordings and notation, music is maintained through its performance, meaning that its circulation and production-through-display are fused. And the evanescence of its performers and listeners-in other words, their mortality-freights transmission and performance with a particular pathos. In the process, the question of authority-how does the piece really go?--takes center stage, to be hashed out among generations of listeners and performers, thus connecting back to the problem of maintaining musical goods over time. Good theory travels and, like any traveler, has always changed when it comes back home.

Jonathan Glasser is visiting assistant professor in the Department of Anthropology at the College of William and Mary. His current book project is titled The Lost Paradise: Andalusi Music in Urban North Africa. He is also an active performer of Middle Eastern and North African music. Wi

\section{Art of an Egg \\ continued from page 12}

Saudi Arabia (revealed elsewhere on the tape)-conveys his appreciation of irony, the cook elaborates in more provocative ways. In turn 10, his eggs, he states, might compel Abu Hamza and his associates to extremes of self-consuming hunger, inciting them to a kind of self-denial achieved not through asceticism but rather through its opposite, a ravenous pleasure that is at once acutely parochial-they are, after all, simply eggs-and also transnational. In turn 12, the speaker redeploys the second-person plural to ratify a more inclusive political community. The eggs are so delicious, he jokes, that Abu Hamza should spread the word among politicians back at home that he and his colleagues have, in fact, entered the lists as top-notch chefs. Such discourse not only positions the cook and associates as purveyors of cultural capital; Abu Hamza himself becomes a humorous figure, an aspect that-illustrated here but also more explicitly elsewhere on the tape-highlights his own penetrability as a global modern subject.

Flagg Miller teaches in the religious studies program at the University of California-Davis. Publications include The Moral Resonance of Arab Media: Audiocassette Poetry and Culture in Yemen (Harvard's Center for Middle Eastern Studies, 2007) and the preface to Poems from Guantánamo: The Detainees Speak (University of Iowa Press, 2007). [W]
Losing Sound

continued from page 11

field of language maintenance to determine the most effective ways forward for endangered music genres. Similarly, linguistic and cultural anthropologists can make an enormous contribution to the development of efforts to sustain musical heritage by illuminating the wider picture of how music (like language) contributes to social identity; interrelates with expressions of cultural beliefs, ideologies and behaviors; and functions in relationship to wider representations of social worlds

We are just beginning to comprehend the effect of rapid global change on the small music genres of the world. The wide-scale threat to these genres may hold wider repercussions for cultural identity, strength and diversity. Music, like language, is one of the key links that ties us to one another-both within and across communities-as well as to the past. The challenge for researchers is to bring clarity and understanding to the forces underlying this threat so that communities, in collaboration with other stakeholders, can establish sustainable futures for their music

Catherine Grant is a PhD candidate and senior research assistant at Queensland Conservatorium Research Centre, Griffith University (Brisbane, Australia). Her research aligns with the 5-year Australian Research Council-funded project Sustainable Futures for Music Cultures: Towards an Ecology of Musical Diversity. More on her research can be found at http://musicsustainability. wordpress.com/about. 四
Sound of Freedom

continued from page 13

off over the edge of the lagoon and beach that gives the community its name moved him to take us on a peripatetic memory journey that traced his and the community's escape from the US invasion forces in 1945. Among the hidden, overgrown and out-of-the-way places along the wandering line of this route we collaborated in making sound recordings that focused on the relationship between their aural character and his memory of the sense of what had happened in 1945 and of his relationship with these places in the period since. These recordings are available with this article through AnthroSource, and I invite you to listen to them now. They were made in the cave beneath Sunabe where he sat with his family listening to the sounds of battle and at the site in the Yanbaru forests of northern Okinawa where he finally met American troops and to which he returned annually with his wife on hiking trips. These sounds, like those of the overflying jets that start the recording and initiated the journey, are placed together to suggest that it is through their relationality and their vibrational affects that we can begin to understand the power and the tragedy of "the sound of freedom."

Rupert Cox is a lecturer in visual anthropology at Manchester University. His interests revolve around the relationships between technology, the senses and media practices as a form of sensory anthropology. He focuses on topics in Japan such as the Zen arts, the idea of copying and aircraft noise. 㖄

\section{AN Call for Proposals}

Anthropology News, the newspaper of the American Anthropological Association, seeks proposals for three upcoming thematic series. Each aims to explore ways anthropologists currently engage with the topic in research, fieldwork, collaborative projects, exhibits, teaching and more.

Upcoming thematic series are:

\section{Sustainability (April): Due December 17}

Restoration and Renovation (May): Due January 21

Memorials and Memorialization (September): Due March 25

\section{Guidelines}

To participate, email a 300-word abstract and 50-100-word biosketch to Anthropology News Managing Editor Amy Goldenberg (agoldenberg@aaanet. org). We welcome proposals for In Focus commentaries, Teaching Strategies, Field Notes articles, photo essays, news stories and interviews. Proposals for photo essays should also include up to five high resolution photographs (tiff or jpg), each with a caption and credit. Selected authors will be notified of their status soon after the proposal deadline, and full articles-commentaries of 1,000-1,300 words or shorter pieces for other article types-will be due eight weeks before the publication date.

Early submissions are encouraged.

www.aaanet.org/issues/anthronews 